\title{
Formação de professores e educadores ambientais: diálogos generativos para a práxis
}

\author{
The formation of environmental teachers and educators: \\ generative dialogues for praxis
}

\author{
Formación de profesores y educadores ambientales: \\ diálogos generativos para la praxis
}

\author{
Laísa Maria Freire ${ }^{1}$ \\ Cae Rodrigues ${ }^{2}$
}

\begin{abstract}
Resumo
No presente trabalho, argumentamos que analisar a produção científica (trabalhos apresentados) do Encontro Pesquisa em Educação Ambiental (EPEA) é trazer os contextos da prática para uma discussão atualizada sobre a Pesquisa em Educação Ambiental (PEA) no Brasil, abrindo caminhos para formulações teóricas em uma perspectiva da práxis. Caracterizamos os trabalhos apresentados no Grupo de Discussão de Pesquisa sobre Formação de professores e educadores ambientais do X EPEA e elaboramos um conjunto de questionamentos generativos como potencial agenda de pesquisa, ou enquadramento metodológico para a (des)(re)construção, ou (re)formulação de pesquisas e ações no âmbito da educação ambiental, com foco na formação de educadores ambientais. Entre os limites conceituais e metodológicos atuais/remanescentes da PEA com foco na formação de professores e educadores ambientais discutidos, destacamos: a persistência do histórico gap entre teoria e prática; a desarticulação das novas teorias em relação aos contextos geo-epistemológicos do campo ambiental; a ausência de diálogos Norte-Sul e a não presença de epistemologias do Sul. A ênfase principal dos questionamentos levantados e da agenda de pesquisa proposta é a potencial superação desses limites no sentido da práxis ambiental.
\end{abstract}

Palavras-chave: Pesquisa em educação ambiental. Ambientalização curricular. Currículo. Ensino superior. Avaliação de produção de conhecimento.

\begin{abstract}
In this paper we argue that analyzing the scientific production (presented communications) from the Brazilian Environmental Education Research Meeting (EPEA) is relevant in bringing the contexts of practice to an updated discussion on Environmental Education Research (EER) in Brazil, paving the way for theoretical formulations in a perspective of praxis. We characterize the works presented in the Research Discussion Group on The formation of environmental teachers and educators of the X EPEA and elaborate a set of generative questions as a potential research agenda, or methodological framework for the (de)(re)construction, or (re)formulation of research and actions in the scope of environmental education, with a focus on the formation of environmental educators. Among the discussed current/remaining conceptual-methodological limits of the EER focusing on the formation of environmental teachers and educators we highlight: the persistence of the historical gap between theory and practice; the disarticulation of new theories in relation to the geo-epistemological contexts of the environmental field; the absence of North-South dialogues and the non-presence of South epistemologies. The main emphasis of the questions raised and the proposed research agenda is the potential to overcome these limits aiming environmental praxis.
\end{abstract}

Keywords: Environmental education research. Curricular environmentalization. Curriculum. Higher education. Knowledge production evaluation.

\footnotetext{
${ }^{1}$ Professora Adjunta na Universidade Federal do Rio de Janeiro (UFRJ), Laboratório de Limnologia, Instituto de Biologia, Programa de Pós-graduação em Educação em Ciências e Saúde do Núcleo de Tecnologia Educacional para a Saúde/UFRJ (http://www.nutes.ufrj.br/) e no Programa de Pós-graduação em Ciências Ambientais e Conservação (NUPEM/UFRJ). laisa@ufrj.br

${ }^{2}$ Professor Adjunto na Faculdade de Educação Física da Universidade Federal de Sergipe. Professor Permanente do Programa de Pós-Graduação em Desenvolvimento e Meio Ambiente - PRODEMA.

rodrigues.cae@gmail.com
} 


\section{Resumen}

En el presente trabajo, sostenemos que analizar la producción científica (comunicaciones presentadas) del Encuentro de Investigación en Educación Ambiental (EPEA) es partir de los contextos de la práctica para una reflexión actual sobre los diálogos de la Investigación en Educación Ambiental (IEA) en Brasil, generando caminos para formulaciones teóricas en una perspectiva de la praxis. Caracterizamos los trabajos presentados en el Grupo de Discusión de Investigación de Formación de profesores y educadores ambientales del X EPEA y elaboramos un conjunto de cuestionamientos generativos como potencial agenda de investigación, o encuadre metodológico para la (des)(re)construcción, o (re)formulación de investigaciones y acciones en el ámbito de la educación ambiental sobre la formación de educadores ambientales. Al discutir los límites conceptuales y metodológicos actuales/remanecientes de la IEA con foco en la formación de profesores y educadores ambientales destacamos: la manutención del gap entre la teoría y la práctica; la desarticulación de las nuevas teorías con relación a los contextos geo-epistemológicos del campo ambiental; la ausencia de diálogos Norte-Sul, resaltando las ausencias de epistemologías desde el Sul global. El énfasis principal de los cuestionamientos realizados y de la agenda de investigación propuesta ha sido la potencial superación de los referidos límites en el sentido de la praxis ambiental.

Palabras clave: Investigación en Educación Ambiental. Ambientalización curricular. Currículo. Enseñanza superior. Evaluación de producción del conocimiento

\section{Para início de conversa...}

A formação de professores e educadores ambientais tem sido tema de práticas, de reorientações curriculares e de políticas públicas. A demanda para o trabalho com educação ambiental (EA) traz, intrinsecamente, a demanda de formação do educador. O campo da pesquisa em educação ambiental (PEA) tem se dedicado a entender potencialidades e limites da formação e atuação dos professores e educadores ambientais no processo educativo. Neste artigo, buscamos caracterizar desafios atuais para a PEA em diálogo com a formação de professores e educadores ambientais. Utilizamos os trabalhos submetidos ao Grupo de Discussão de Pesquisa (GDP) sobre formação de professores e educadores ambientais do X Encontro Pesquisa em Educação Ambiental (EPEA) como material empírico de análise.

Caracterizamos os trabalhos submetidos ao GDP do EPEA como um acervo que contribui com a discussão da PEA no país e sua análise permite traçar uma agenda de compromissos que podem ser tema dos encontros do GDP em futuras edições do EPEA. Em seguida, elaboramos uma caracterização geral dos trabalhos apresentados e uma discussão sobre as principais sinergias, idiossincrasias e pontos silenciosos apresentados nos trabalhos de formação, de modo a promover uma série de questionamentos que pretendem ir para além deste texto.

Observamos que as pesquisas sobre formação têm, em maior ou menor medida, debatido esses desafios a partir de investigações que buscam caracterizar os processos de formação a partir de olhares teóricos que se situaram nos estudos do currículo, na pedagogia históricocrítica dos conteúdos e em diálogos com novas teorias (novos materialismos; novas etnografias) que são apresentadas como alternativas a algo anterior, especialmente em contextos de novas realidades a partir de uma concepção pós (colonial; humana; estrutural). Nos debruçamos sobre os desafios que os olhares teóricos trazem aos processos de ambientalização curricular e de formação de educadores ambientais, considerando as possibilidades e limitações da abordagem (inter)disciplinar da EA, especialmente, no contexto do enfraquecimento atual das estruturas da EA no Brasil.

Nesse sentido, ao analisarmos os trabalhos apresentados, estabelecemos um diálogo generativo motivado pelos temas e questões dos trabalhos com o ensejo de contribuir para uma agenda de PEA com foco na formação de educadores ambientais, incluindo o futuro do GDP do EPEA. Sugerimos que as PEAs identifiquem que ações capilares permanecem nos processos 
formativos e estabeleçam uma crítica explanatória sobre os efeitos do desmonte de políticas públicas nos processos educativos brasileiros.

\section{Porque analisar a produção de trabalhos do EPEA para discussão da pesquisa em educação ambiental no Brasil?}

A PEA, no Brasil, tem sido realizada, sobretudo, por pesquisadores e estudantes vinculados a programas de pós-graduação de diferentes áreas de conhecimento, e com crescimento a partir da década de 1990 (FRACALANZA, 2004; SOUZA; SALVI, 2012; FRACALANZA et al., 2013). Embora recente, ela tem uma contribuição significativa para entendimento do campo. Segundo Souza e Salvi (2012), a PEA torna-se mais estruturada no início do século XXI e, atualmente, encontra-se divulgada por diferentes meios de comunicação acadêmicos, como periódicos especializados (Revista do Mestrado em Educação Ambiental, Revista Brasileira de Educação Ambiental, Revista Eletrônica de Educação Ambiental em Ação, Revista de Pesquisa em Educação Ambiental) e eventos como o EPEA (desde 2001) e o GT-22 da Associação Nacional de Pós-Graduação e Pesquisa em Educação (ANPEd) (desde 2002). Além disso, a produção da área está organizada na plataforma EArte, que permite ter acesso a teses e dissertações de EA.

No que se refere ao EPEA, o primeiro foi realizado em 2001, de modo a suprir com a necessidade de compartilhar as PEAs que vinham sendo realizadas por um conjunto de programas de pós-graduação no estado de São Paulo. A importância da criação do evento foi estabelecer um locus para discussão sobre a produção de conhecimentos na área que, muitas vezes, fica pulverizada em eventos de outras áreas ou em ações de militância, por sua ontologia transdisciplinar e seu compromisso de engajamento social. Desse modo, o EPEA poderia contribuir para avanços na PEA oferecendo à comunidade de pesquisadores um espaço acadêmico para a discussão. Desde 2001, foram realizados dez encontros que buscam discutir, analisar e divulgar trabalhos de PEA, aprofundando e debatendo suas abordagens epistemológicas e metodológicas. Nesses dez anos de eventos (quase vinte anos de rede), a rede de pesquisadores se fortaleceu e, junto com o desenvolvimento de outros espaços de troca, foi amadurecendo e formando novas gerações.

O EPEA começou a nível local, mas foi, ao longo dos anos, ganhando uma relevância nacional com diálogos internacionais e, a partir da oitava edição, passou a ser realizado também fora do estado de São Paulo. Desde então, o EPEA já foi realizado no Rio de Janeiro (RJ) (2015), em Juiz de Fora (MG) (2017) e São Cristóvão (SE) (2019). Essa alternância de lugares gerou um vínculo maior entre a rede de colaboradores, uma vez que os grupos de PEA do estado de São Paulo mantiveram a colaboração na organização geral de cada evento em parceria com as equipes locais.

Uma singularidade dos EPEA é a constituição, a partir da terceira edição do encontro, em 2005, dos GDP, propostos "como uma nova modalidade para a discussão, em grupos, das pesquisas apresentadas no evento" (CARVALHO, 2016, p.151). A proposta é que os GDPs possam promover um espaço de socialização, aprofundamento e ampliação das discussões sobre cada trabalho, a partir do foco temático de cada GDP. Além disso, ao submeterem trabalhos ao evento, já elegendo um GDP, os autores estabelecem uma relação de identificação com o GDP a partir de sua temática de pesquisa. Essa identificação é significativa para a criação de redes de pesquisa que se estabelecem no encontro a partir dos diferentes GDPs, tanto no sentido de próximas edições do encontro, como de outras atividades colaborativas de pesquisa (sendo esse artigo um exemplo disso).

O GDP de formação de educadores/professores iniciou-se em 2007, no IV EPEA (CARVALHO, 2016). Embora tenhamos observado que nem sempre o trabalho submetido ao GDP de formação tem a formação como objeto de pesquisa, entendemos que o pesquisador 
escolheu ser localizado na discussão sobre formação quando o trabalho é submetido. Nesse sentido, analisar os trabalhos do GDP permite entender os problemas de pesquisa que são colocados sobre os processos formativos no campo da EA. Justificamos que, ainda que a formação seja (em alguns trabalhos) contexto de pesquisa e não objeto, o trabalho pode trazer uma discussão de pesquisa que vale a pena ser analisada e discutida à luz da formação.

A partir da configuração do GDP de formação, as discussões e os caminhos da pesquisa sobre formação de educadores/professores são sistematizados ao final de cada evento. Questões sobre a identidade do educador ambiental já foram amplamente discutidas, bem como a formação do educador em espaços universitários vinculados a programas como o PIBID ou vinculados a programas, projetos ou ações de extensão (FREIRE; FIGUEIREDO; GUIMARÃES, 2016), problematizando a experiência da formação em EA no ensino superior fora de espaços tradicionalmente disciplinares. Além disso, a partir dos trabalhos do IX EPEA, Figueiredo e Freire (2018) observaram que os espaços e os lugares da prática são o foco privilegiado das pesquisas do GDP de formação que respondem a políticas públicas, ressignificando e reinterpretando a formação. Sendo assim, as políticas não só foram orientadoras de práticas de formação, mas de questões para pesquisa.

O X EPEA, realizado no estado de Sergipe, ampliou o diálogo com pesquisadores vinculados a instituições das regiões Norte e Nordeste do país, trazendo novos perfis de pesquisa para o GDP de formação. A organização do Grupo de Estudo e Pesquisa em Educação Ambiental de Sergipe (GEPEASE) proporcionou um evento de modo a estreitar o diálogo com as pesquisas realizadas em âmbito nacional e com as discussões do contexto político atual.

O cenário vigente de desmontes e reorientações nas políticas ambientais e educacionais no Brasil teve reflexos na programação e nas discussões realizadas no encontro. Compreendemos que parte relevante do necessário movimento de resistência perpassa pela análise das dificuldades da/para a PEA nesse cenário, além de consequentes (res)significações, (re)caracterizações e (re)definições do lugar da (P)EA nas políticas públicas e nos currículos de formação, incluindo o desvelar de transformações em andamento e o vislumbrar de novas possibilidades. A partir desse panorama, argumentamos que investigar a produção do GDP é trazer os contextos da prática para uma reflexão atualizada sobre os diálogos da PEA no Brasil.

\section{Análise geral dos trabalhos enviados ao GDP Formação de professores e educadores ambientais do X EPEA e formulação de questões generativas para a PEA}

Ao analisar as produções apresentadas no GDP Formação de professores e educadores ambientais as seguintes categorias foram destacadas: (a) Título do trabalho (categoria de identificação); (b) Filiação dos autores (categoria estatística - representatividade geográfica); (c) Tema geral (categoria estatística - representatividade das temáticas abordadas); (d) Questão central abordada (categoria de análise qualitativa - especificidades temáticas e de abordagem entre os temas gerais abordados); (e) Questionamentos críticos (categoria de análise qualitativa - identificação de pontos silenciosos que limitam a práxis das pesquisas apresentadas). Os dados referentes às categorias (a)-(d) são apresentados no Quadro 1. Os dados referentes à categoria (e) são apresentados ao final desta seção, sendo base para a apresentação de uma análise crítica sobre limites conceituais e metodológicos atuais/remanescentes da PEA, com foco na formação de professores e educadores ambientais, reconhecendo-se as possibilidades e limitações de um estudo de pequena escala a partir da análise de trabalhos apresentados a um GDP temático do X EPEA.

\begin{tabular}{|c|c|c|c|}
\hline Título do trabalho & $\begin{array}{c}\text { Filiação dos } \\
\text { autores }\end{array}$ & Tema geral & Questão central abordada \\
\hline
\end{tabular}




\begin{tabular}{|c|c|c|c|}
\hline $\begin{array}{l}\text { Educação ambiental } \\
\text { crítica e pedagogia } \\
\text { histórico crítica: uma } \\
\text { sintonia possível para a } \\
\text { formação de professores } \\
\text { crítico-dialéticos }\end{array}$ & $\begin{array}{l}\text { Secretaria de } \\
\text { Educação do } \\
\text { Estado de } \\
\text { Sergipe, Instituto } \\
\text { de Química, } \\
\text { UFBA }\end{array}$ & $\begin{array}{l}\text { Formação de } \\
\text { professores em EA } \\
\text { (perspectiva } \\
\text { crítico-dialética) }\end{array}$ & $\begin{array}{l}\text { Como a mediação didática, como definida } \\
\text { pela Pedagogia Histórico-Crítica, pode se } \\
\text { concretizar num procedimento didático } \\
\text { essencial ao ato pedagógico de professores } \\
\text { dedicados à práxis da Educação Ambiental } \\
\text { Crítica formal? }\end{array}$ \\
\hline $\begin{array}{l}\text { Produção de significados } \\
\text { a partir de rodas de } \\
\text { conversa: a promoção de } \\
\text { espaços dialógicos como } \\
\text { estratégia para formação } \\
\text { continuada em Educação } \\
\text { Ambiental }\end{array}$ & $\begin{array}{c}\text { USP, campus São } \\
\text { Paulo }\end{array}$ & $\begin{array}{l}\text { Formação } \\
\text { continuada } \\
\text { (espaços } \\
\text { dialógicos) }\end{array}$ & $\begin{array}{l}\text { Uma formação continuada que valorize } \\
\text { espaços dialógicos, como rodas de conversa, } \\
\text { pode ser uma estratégia válida para a } \\
\text { formação de educadores ambientais em uma } \\
\text { perspectiva mais crítica? }\end{array}$ \\
\hline $\begin{array}{l}\text { A dimensão ambiental da } \\
\text { História na BNCC para } \\
\text { os anos iniciais e as } \\
\text { implicações para a } \\
\text { formação docente }\end{array}$ & UFS & $\begin{array}{l}\text { Ambientalização } \\
\text { curricular } \\
\text { (dimensões } \\
\text { ambientais na/da } \\
\text { Base Nacional } \\
\text { Comum } \\
\text { Curricular) }\end{array}$ & $\begin{array}{l}\text { Como a Universidade contribui para a } \\
\text { formação docente para atuação nos anos } \\
\text { iniciais do Ensino Fundamental na } \\
\text { perspectiva da dimensão ambiental do ensino } \\
\text { de história? }\end{array}$ \\
\hline $\begin{array}{l}\text { Tendências da produção } \\
\text { científica na interface da } \\
\text { formação de professores } \\
\text { e educação ambiental }\end{array}$ & UFRPE & $\begin{array}{l}\text { Formação de } \\
\text { professores em EA } \\
\text { (avaliação de } \\
\text { produção } \\
\text { científica) }\end{array}$ & $\begin{array}{l}\text { Quais são as tendências da produção } \\
\text { científica situada na interface da educação } \\
\text { ambiental e da formação de professores, no } \\
\text { período de } 2001 \text { a } 2017 \text {, em eventos } \\
\text { científicos nacionais do Brasil? }\end{array}$ \\
\hline $\begin{array}{l}\text { A pesquisa-ação como } \\
\text { ferramenta da prática } \\
\text { pedagógica nos cursos de } \\
\text { pedagogia: um olhar } \\
\text { sobre a formação de } \\
\text { pedagogos no que se } \\
\text { refere à educação } \\
\text { ambiental. }\end{array}$ & UFS & $\begin{array}{l}\text { Formação de } \\
\text { professores em EA } \\
\text { (pesquisa-ação na } \\
\text { formação do } \\
\text { pedagogo) }\end{array}$ & $\begin{array}{l}\text { A pesquisa-ação pode ser utilizada como } \\
\text { ferramenta da ação pedagógica na formação } \\
\text { dos pedagogos, no tocante à educação } \\
\text { ambiental, de modo a instrumentalizá-los } \\
\text { para uma prática profissional que contribua } \\
\text { para a conservação do meio ambiente? }\end{array}$ \\
\hline $\begin{array}{l}\text { Compreensões sobre a } \\
\text { temática ambiental e a } \\
\text { formação inicial de } \\
\text { professores de ciências e } \\
\text { biologia }\end{array}$ & $\begin{array}{l}\text { UNEMAT; } \\
\text { UNIFEI }\end{array}$ & $\begin{array}{l}\text { Formação de } \\
\text { professores em EA } \\
\text { (levantamento de } \\
\text { percepções sobre a } \\
\text { formação inicial) }\end{array}$ & $\begin{array}{c}\text { De que modo a compreensão de licenciandos } \\
\text { sobre a temática ambiental pode ser um } \\
\text { obstáculo para realização de trabalhos } \\
\text { críticos? }\end{array}$ \\
\hline
\end{tabular}




\begin{tabular}{|c|c|c|c|}
\hline $\begin{array}{l}\text { Produções narrativas da } \\
\text { educação ambiental na } \\
\text { formação de professores }\end{array}$ & UFES & $\begin{array}{l}\text { Formação de } \\
\text { professores em EA } \\
\text { (perspectiva pós- } \\
\text { colonial) }\end{array}$ & $\begin{array}{l}\text { Como podemos pensar a formação de } \\
\text { professores em EA a partir de outras } \\
\text { perspectivas, problematizando a } \\
\text { racionalidade exclusivista que valoriza o } \\
\text { pensamento único e buscando o diálogo com } \\
\text { essa ciência supostamente hegemônica e com } \\
\text { os saberes das ciências sociais, saberes } \\
\text { religiosos, tradicionais e, também, do senso } \\
\text { comum? }\end{array}$ \\
\hline $\begin{array}{l}\text { A importância da } \\
\text { educação socioambiental } \\
\text { na formação do docente } \\
\text { da educação infantil }\end{array}$ & UFRPE & $\begin{array}{l}\text { Formação de } \\
\text { professores em EA } \\
\text { (educação } \\
\text { socioambiental na } \\
\text { formação docente } \\
\text { do ensino infantil) }\end{array}$ & $\begin{array}{l}\text { Como o docente da educação infantil pode } \\
\text { atuar na promoção de processos de EA } \\
\text { orientados por uma visão integrada, } \\
\text { holística, da questão ambiental? }\end{array}$ \\
\hline $\begin{array}{c}\text { As percepções dos } \\
\text { discentes de ciências } \\
\text { naturais como pilar para } \\
\text { uma educação ambiental } \\
\text { holística na Amazônia } \\
\text { amapaense }\end{array}$ & $\begin{array}{l}\text { Universidade do } \\
\text { Estado do Amapá } \\
\text { (UEAP) }\end{array}$ & $\begin{array}{l}\text { Formação de } \\
\text { professores em EA } \\
\text { (levantamento de } \\
\text { percepções sobre a } \\
\text { formação inicial) }\end{array}$ & $\begin{array}{c}\text { Como podemos pensar a formação de } \\
\text { professores em EA a partir de perspectivas } \\
\text { interdisciplinares? }\end{array}$ \\
\hline $\begin{array}{l}\text { A formação discursiva no } \\
\text { campo da pesquisa em } \\
\text { formação continuada de } \\
\text { professores em educação } \\
\text { ambiental }\end{array}$ & UNESP- RC & $\begin{array}{c}\text { Formação } \\
\text { continuada (estado } \\
\text { da arte sobre } \\
\text { formação } \\
\text { continuada de } \\
\text { professores) }\end{array}$ & $\begin{array}{c}\text { Quais são as tendências da produção } \\
\text { científica sobre formação continuada de } \\
\text { professores em EA (formações discursivas)? }\end{array}$ \\
\hline $\begin{array}{l}\text { Desafios e perspectivas } \\
\text { da educação ambiental na } \\
\text { formação docente }\end{array}$ & UFPA & $\begin{array}{l}\text { Formação de } \\
\text { professores em EA } \\
\text { (levantamento de } \\
\text { percepções sobre a } \\
\text { formação inicial) }\end{array}$ & $\begin{array}{c}\text { O que informam as concepções dos alunos } \\
\text { do curso de pedagogia sobre o meio } \\
\text { ambiente e EA constituindo desafios para a } \\
\text { EA no ES? }\end{array}$ \\
\hline $\begin{array}{l}\text { Formação in lócus: } \\
\text { atividades de Educação } \\
\text { Ambiental no Parque } \\
\text { Natural Municipal de } \\
\text { Nova Iguaçu- RJ }\end{array}$ & $\begin{array}{l}\text { UFRRJ, campus } \\
\text { Nova Iguaçu }\end{array}$ & $\begin{array}{c}\text { Formação de } \\
\text { professores em EA } \\
\text { (formação inicial } \\
\text { em pedagogia e } \\
\text { geografia) }\end{array}$ & $\begin{array}{l}\text { Como podemos criar espaços de formação } \\
\text { valorizados pelos estudantes universitários? }\end{array}$ \\
\hline $\begin{array}{c}\text { Prática de ecologia e } \\
\text { vivências participativas: } \\
\text { um olhar para a formação } \\
\text { de professores de } \\
\text { biologia }\end{array}$ & $\begin{array}{l}\text { Universidade } \\
\text { Federal de } \\
\text { Pernambuco } \\
\text { (UFPE), } \\
\text { Fundação } \\
\text { Joaquim Nabuco } \\
\text { (FUNDAJ) }\end{array}$ & $\begin{array}{l}\text { Formação de } \\
\text { professores em EA } \\
\text { (formação inicial } \\
\text { em biologia) }\end{array}$ & $\begin{array}{c}\text { Narrativas ambientais como promotoras de } \\
\text { novas epistemologias na formação de } \\
\text { professores? }\end{array}$ \\
\hline $\begin{array}{c}\text { Novas reflexões sobre o } \\
\text { ensino de } \\
\text { sustentabilidade nas } \\
\text { faculdades de arquitetura } \\
\text { e urbanismo }\end{array}$ & $\begin{array}{l}\text { Universidade } \\
\text { Federal do Rio } \\
\text { Grande do Sul }\end{array}$ & \begin{tabular}{|} 
Ambientalização \\
curricular \\
(inserção da \\
sustentabilidade no \\
curso de \\
arquitetura) \\
\end{tabular} & $\begin{array}{c}\text { Que aspectos priorizar na formação para a } \\
\text { sustentabilidade em uma Faculdade de } \\
\text { Arquitetura e Urbanismo? }\end{array}$ \\
\hline
\end{tabular}




\begin{tabular}{|c|c|c|c|}
\hline $\begin{array}{l}\text { Ambientalização na } \\
\text { Universidade: um estudo } \\
\text { sobre teses e dissertações } \\
\text { em Educação Ambiental } \\
\text { - primeiras } \\
\text { aproximações. }\end{array}$ & $\begin{array}{l}\text { Unesp, campus } \\
\text { Rio Claro }\end{array}$ & $\begin{array}{l}\text { Ambientalização } \\
\text { curricular (análise } \\
\text { de produção } \\
\text { científica) }\end{array}$ & $\begin{array}{l}\text { Quais são as tendências da produção } \\
\text { científica - teses e dissertações - que usam o } \\
\text { referencial da ambientalização e da } \\
\text { ambientalização curricular no Brasil? }\end{array}$ \\
\hline $\begin{array}{c}\text { Ambientalização } \\
\text { Curricular e Cultura da } \\
\text { Sustentabilidade na } \\
\text { universidade pública: } \\
\text { pluralismo e diversidade } \\
\text { na educação ambiental }\end{array}$ & USP & $\begin{array}{l}\text { Ambientalização } \\
\text { curricular (no } \\
\text { ensino superior) }\end{array}$ & $\begin{array}{l}\text { Como a ambientalização curricular e a } \\
\text { cultura da sustentabilidade estão } \\
\text { incorporadas na formação dos estudantes de } \\
\text { uma universidade pública paulista (Brasil), } \\
\text { segundo relatos de professores/as e } \\
\text { coordenadores/as de cursos de graduação? }\end{array}$ \\
\hline $\begin{array}{c}\text { A Educação Ambiental } \\
\text { no ensino superior: a } \\
\text { inserção disciplinar nos } \\
\text { cursos de graduação da } \\
\text { Universidade Federal do } \\
\text { Estado do Rio de Janeiro } \\
\text { (UNIRIO) }\end{array}$ & UFRJ, UNIRIO & $\begin{array}{l}\text { Ambientalização } \\
\text { curricular (no } \\
\text { ensino superior) }\end{array}$ & $\begin{array}{l}\text { Quais foram os marcos reguladores do } \\
\text { processo de institucionalização da EA como } \\
\text { disciplina específica nos cursos de graduação } \\
\text { de uma Universidade Federal do Estado do } \\
\text { Rio de Janeiro, no Brasil? }\end{array}$ \\
\hline $\begin{array}{l}\text { A estética na Educação } \\
\text { Ambiental a partir de } \\
\text { experiências em uma } \\
\text { Trilha Interpretativa com } \\
\text { educadores ambientais }\end{array}$ & UFRJ & Estética e EA & $\begin{array}{c}\text { Quais aspectos estéticos são mobilizados por } \\
\text { educadores ambientais, em um texto } \\
\text { narrativo, após a realização de uma Trilha } \\
\text { Interpretativa na Floresta Nacional de } \\
\text { Carajás? }\end{array}$ \\
\hline $\begin{array}{c}\text { Educação Ambiental, } \\
\text { Formação de Professores } \\
\text { e Currículo: uma análise } \\
\text { dos discursos produzidos } \\
\text { no cenário educacional } \\
\text { (2000-2016). }\end{array}$ & UERJ, UFRJ & $\begin{array}{l}\text { Ambientalização } \\
\text { curricular } \\
\text { (avaliação de } \\
\text { produção } \\
\text { científica) }\end{array}$ & $\begin{array}{l}\text { Quais tendências discursivas sobre os temas } \\
\text { formação de professores, currículo e EA } \\
\text { podem ser identificadas em pesquisas } \\
\text { produzidas entre os anos } 2000-2016 \text { que } \\
\text { foram publicadas em periódicos brasileiros } \\
\text { qualificados nos extratos A1 e A2 (Qualis- } \\
\text { Capes) na área de Educação? }\end{array}$ \\
\hline $\begin{array}{l}\text { Formação continuada em } \\
\text { educação ambiental: uma } \\
\text { investigação das } \\
\text { produções nas nove } \\
\text { edições do EPEA }\end{array}$ & UFS & $\begin{array}{l}\text { Formação } \\
\text { continuada } \\
\text { (avaliação de } \\
\text { produção } \\
\text { científica) }\end{array}$ & $\begin{array}{c}\text { As tendências das pesquisas sobre formação } \\
\text { continuada de professores que atuam com } \\
\text { EA, apresentadas em edições anteriores do } \\
\text { EPEA, corroboraram com o } \\
\text { desenvolvimento da perspectiva crítica da } \\
\text { EA? }\end{array}$ \\
\hline $\begin{array}{c}\text { Utilização de jogos } \\
\text { educacionais da fauna } \\
\text { amazônica ameaçada de } \\
\text { extinção na formação de } \\
\text { multiplicadores } \\
\text { ambientais }\end{array}$ & $\begin{array}{c}\text { CEPAM/ICMBio, } \\
\text { UFAM }\end{array}$ & $\begin{array}{l}\text { Formação } \\
\text { continuada (jogos } \\
\text { ecopedagógicos) }\end{array}$ & $\begin{array}{c}\text { A construção participativa de recursos } \\
\text { didáticos pela/para a abordagem lúdica dos } \\
\text { problemas cotidianos permite o } \\
\text { desenvolvimento de práticas ecopedagógicas } \\
\text { que vislumbram a EA crítica? }\end{array}$ \\
\hline
\end{tabular}




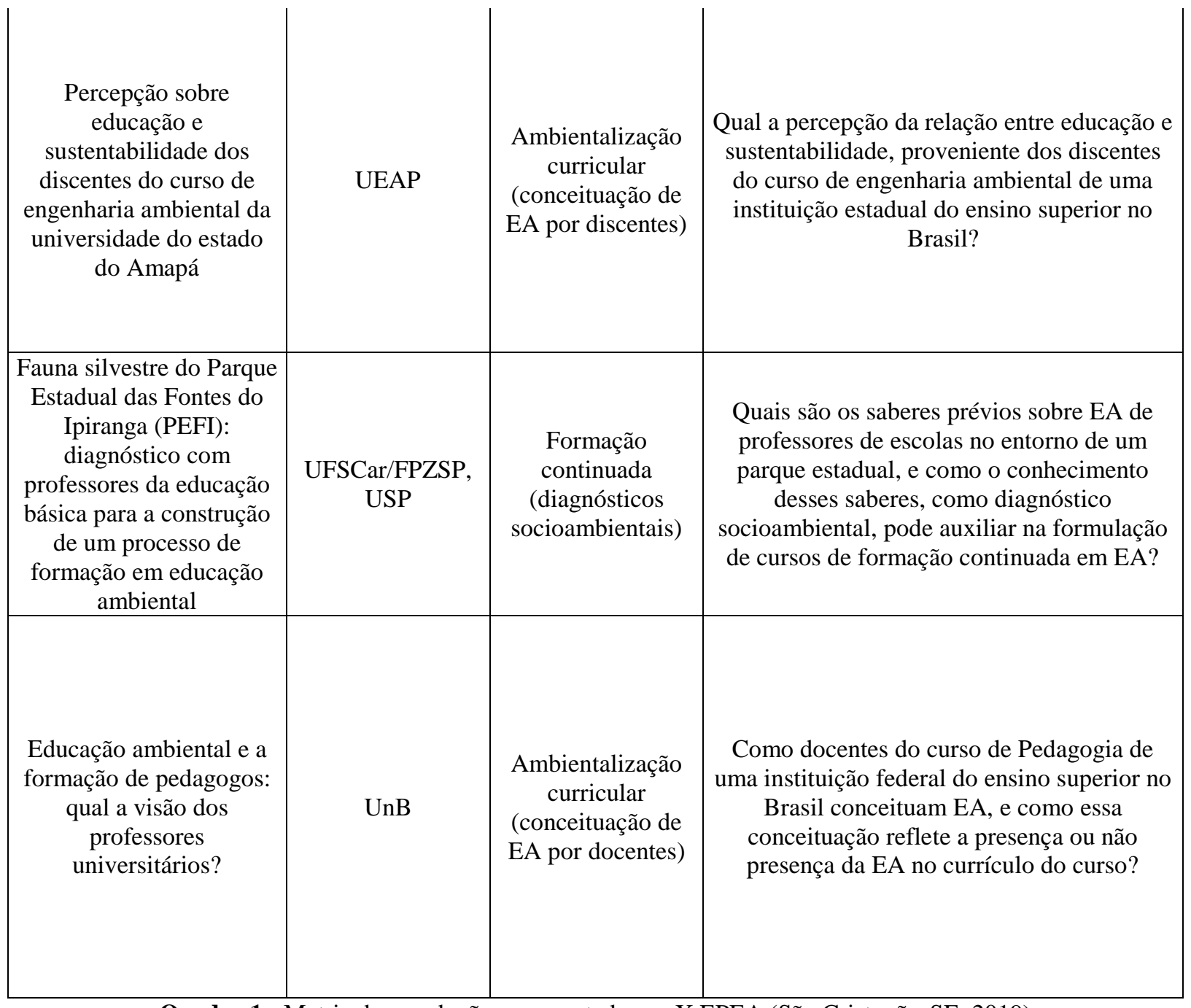

Quadro 1 - Matriz das produções apresentadas no X EPEA (São Cristovão-SE, 2019)

Fonte: Elaborado pelos autores

A representatividade geográfica de filiação dos autores pode ser visualizada na Figura 1. Observamos que a maior quantidade dos autores ainda é proveniente da região Sudeste do país. A alta representatividade conjunta das contribuições das regiões Norte e Nordeste pode estar respondendo ao fato de o evento ter sido realizado em Sergipe, facilitando o deslocamento dos pesquisadores para apresentação de suas pesquisas no evento. 


\section{Filiação dos autores}

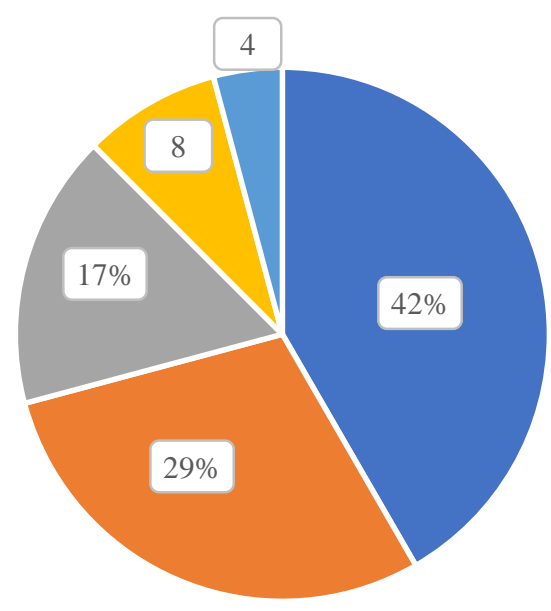

- Sudeste (10) - Nordeste (7) - Norte (4) $\quad$ - Centro-Oeste (2) - Sul (1)

Figura 1 - Representatividade geográfica de filiação dos autores que apresentaram trabalhos no GDP Formação de professores e educadores ambientais no X EPEA

Fonte: autores

A representatividade das temáticas abordadas nos trabalhos apresentados no GDP pode ser visualizada na Figura 2. As temáticas foram categorizadas em quatro grupos gerais: (a) Formação de professores em EA (maioria sobre formação inicial); (b) Ambientalização curricular; (c) Formação continuada; (d) Estética e EA. Essa categorização por aproximação temática, conjuntamente com um olhar sobre as especificidades temáticas e de abordagem apresentadas na Tabela 1, permite uma análise sobre como as pesquisas em formação de professores e educadores ambientais evidenciam, de maneira geral, três aspectos principais: (a) diferentes abordagens/perspectivas para a inserção das questões ambientais na formação de educadores (majoritariamente, professores); (b) as estruturas específicas de inserção das questões ambientais na formação do professor em diferentes áreas/disciplinas acadêmicas (formação inicial); (c) as dinâmicas de inserção da questão ambiental nos currículos (ambientalização curricular), incluindo particularidades desse processo em diferentes áreas/disciplinas acadêmicas (majoritariamente, no ensino superior). Como particularidade idiossincrática, foi apresentada uma pesquisa sobre a mobilização de aspectos estéticos em uma vivência de EA, comprovando o argumento de Payne et al. (2018) sobre a carência, ou mesmo ausência, das dimensões estéticas e da afetividade na PEA. 


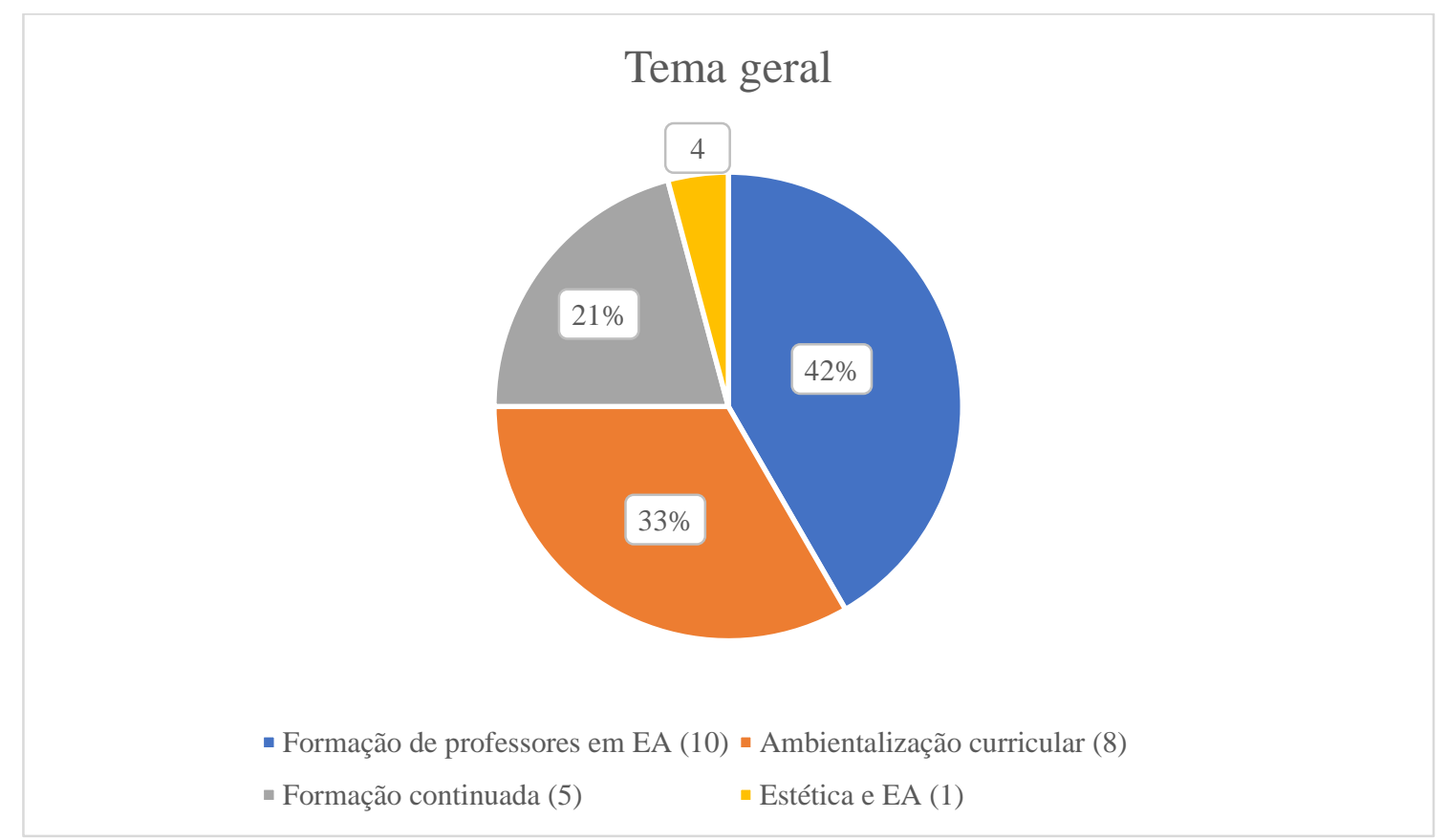

Figura 2 - Representatividade das temáticas abordadas em trabalhos apresentados no GDP Formação de professores e educadores ambientais no X EPEA

Fonte: autores

Após a organização da categoria de identificação (títulos dos trabalhos) e das categorias estatísticas (filiação dos autores e temática geral), cada texto apresentado no GDP Formação de professores e educadores ambientais foi analisado a partir de uma leitura crítica para a formulação das categorias de análise qualitativa, compreendendo: a identificação das questões centrais abordadas nos trabalhos (apresentadas no Quadro 1), complementando a análise dos temas gerais pelo apontamento de especificidades temáticas e das diferentes abordagens aos temas; e a formulação de questionamentos a partir da identificação de limites e pontos silenciosos nas pesquisas apresentadas, considerando, sobretudo, o potencial generativo das pesquisas em relação à práxis. Damos ênfase, agora, a esses questionamentos.

$\mathrm{O}$ foco dos questionamentos no potencial generativo das pesquisas em relação à práxis vem da compreensão, compartilhada com Payne et al. (2018, p.94), que:

\footnotetext{
Em suas pressuposições ontológicas, interesses epistemológicos e deliberações metodológicas, a teoria crítica na pesquisa em educação ambiental (PEA) é, simultaneamente, científica, normativamente (e reflexivamente) crítica e, de forma não idealista, prática. Desse modo, é uma teoria da prática, ou da práxis.
}

Para cada texto analisado foram elaborados entre um e três questionamentos, sendo que alguns questionamentos se repetiram em diferentes publicações de uma mesma área temática. Para a apresentação neste texto os questionamentos foram reorganizados e agrupados para a formulação de questões generativas, diretamente associadas às temáticas centrais identificadas na análise do corpus da pesquisa, relembrando: (a) diferentes abordagens/perspectivas para a inserção das questões ambientais na formação de educadores; (b) particularidades da inserção das questões ambientais na formação do professor em diferentes áreas/disciplinas acadêmicas; (c) processos de ambientalização curricular.

$\mathrm{O}$ conceito de questões generativas é inspirado no conceito freiriano de temas geradores, compreendido como temas com grande potencial de desdobramento em muitos outros temas, discussões e ações, independente da natureza de sua compreensão ou conceituação (FREIRE, 1981). Como questões generativas, destacando-se o potencial de 
transferência (não generalização) dos questionamentos propostos para diferentes contextos da PEA (considerando-se as particularidades geo-epistemológicas de cada contexto - Canaparo, 2009), mais do que um questionamento pontual sobre um corpus específico, propomos o conjunto de questionamentos a seguir como potencial agenda de pesquisa, ou framework metodológico (parcial ou integral) para a (des)(re)construção, ou (re)formulação de pesquisas e ações no âmbito da EA com foco na formação de educadores ambientais.

- Quais são as principais dificuldades para a superação da desconexão entre a teoria e a prática (theory-practice gap) no sentido da práxis? Quais ações/procedimentos metodológicos efetivamente ${ }^{3}$ sustentam a superação dessas dificuldades nos contextos específicos da formação de educadores ambientais? Quais ações efetivamente valorizam a práxis ambiental nos currículos de formação de professores?

- Diante da diversidade sociocultural que é representada em uma sala de aula em um país heterogêneo como o Brasil, como efetivamente organizar a pluralidade de saberes ambientais em (diferentes) contextos curriculares e de formação de educadores? Em que medida as propostas (teorias; ações) de formação de educadores ambientais efetivamente dialogam com as demandas escolares? Que sentidos de cidadania estamos efetivamente construindo a partir de pesquisas em EA e de práticas curriculares ambientalizadas?

- Como diferentes abordagens/perspectivas teórico-metodológicas adotadas no campo ambiental, como pesquisa-ação, narrativas etnográficas e fenomenológicas, enquadramentos (pós)críticos e associados à (teoria da) complexidade, abordagens lúdicas para a práxis ecopedagógica, diagnósticos socioambientais ${ }^{4}$, entre diversas outras, efetivamente contribuem para a (re)orientação dos processos de formação e de pesquisa em EA no sentido da educação justa?

- Quais são os escopos e desígnios da universidade e da ciência na sociedade atual e como essa (re)orientação influencia (direta e indiretamente) os processos de ambientalização curricular e de formação de educadores ambientais? Compreendendo o "não-lugar" da perspectiva ambiental nas estruturas curriculares do Brasil e os desafios da ambientalização curricular em âmbito global, quais são as principais dificuldades para a ampliação dos processos de ambientalização curricular em contextos atuais e quais ações efetivamente contribuem para a superação dessas dificuldades? Compreendendo a discussão a partir das dinâmicas local/regional $\leftrightarrow$ global, de que modo os indicadores globais de ambientalização curricular consideram desafios de países do Sul global?

- Como diferentes experiências (disciplinares/curriculares; "práticas") de EA efetivamente contribuem para a (re)formulação dos sentidos e significados de questões centrais do campo ambiental, por exemplo, "meio ambiente", "natureza", "sustentável", "ecológico"?

- Como as redes de ambientalização curricular efetivamente contribuem para processos de (re)construção e (re)delimitação da(s) identidade(s) do educador ambiental no âmbito da formação e da pesquisa em EA?

- Quais são as principais limitações, que precisam ser reconhecidas e discutidas, de processos dialógicos na formação de educadores ambientais? Quais são as principais dificuldades para a construção/constituição de espaços dialógicos e quais ações efetivamente contribuem para o enfrentamento dessas dificuldades?

- Reconhecendo-se a relevância do contexto geo-cultural/histórico como fator condicionante da forma como aspectos estéticos são mobilizados em uma experiência (na natureza), quais ações/procedimentos metodológicos efetivamente contribuem para a construção de práticas e

\footnotetext{
${ }^{3}$ Nesse texto, o significado de "efetivamente" compreende contextos não-idealistas (ver Fay, 1987; Rodrigues, 2016) e sustentados empiricamente, condições essenciais para a práxis (RODRIGUES, 2020b).

${ }^{4}$ As abordagens citadas aparecem, direta ou indiretamente, no corpus de análise dessa pesquisa (textos apresentados no GDP "Formação de professores e educadores ambientais" do X EPEA).
} 
pesquisas ambientais que possuam potencial de transferibilidade (que sejam generativas) e evitem a reprodução de generalizações idealistas?

- Quais são as limitações, que precisam ser reconhecidas e discutidas, de pesquisas que avaliam a produção científica relacionada ao campo ambiental e quais ações/procedimentos metodológicos efetivamente contribuem para a superação dessas limitações? De que forma podemos efetivamente usar/aplicar dados relativos a avaliações da produção científica relacionada ao campo ambiental no sentido de avanços do campo em suas estruturas conceituais, metodológicas e pedagógicas?

\section{PEA com ênfase na formação de educadores ambientais: contribuindo para o diálogo}

A partir das "questões generativas" que emergiram da leitura crítica dos trabalhos enviados ao GDP "Formação de professores e educadores ambientais" do X EPEA, elaboramos um "mapa mental" (Figura 3) indicando "pontos sensíveis" a serem considerados na elaboração, revisão ou avaliação de pesquisas com ênfase na formação de educadores ambientais. Por "pontos sensíveis" compreendemos questões/ações relevantes para a superação de limites e pontos silenciosos observados no conjunto das pesquisas apresentadas, considerando, sobretudo, a carência/ausência de potencial generativo das pesquisas em relação à práxis.

\section{Indicação efetiva dos sentidos de cidadania construídos em pesquisas em EA e práticas curriculares ambientalizadas}

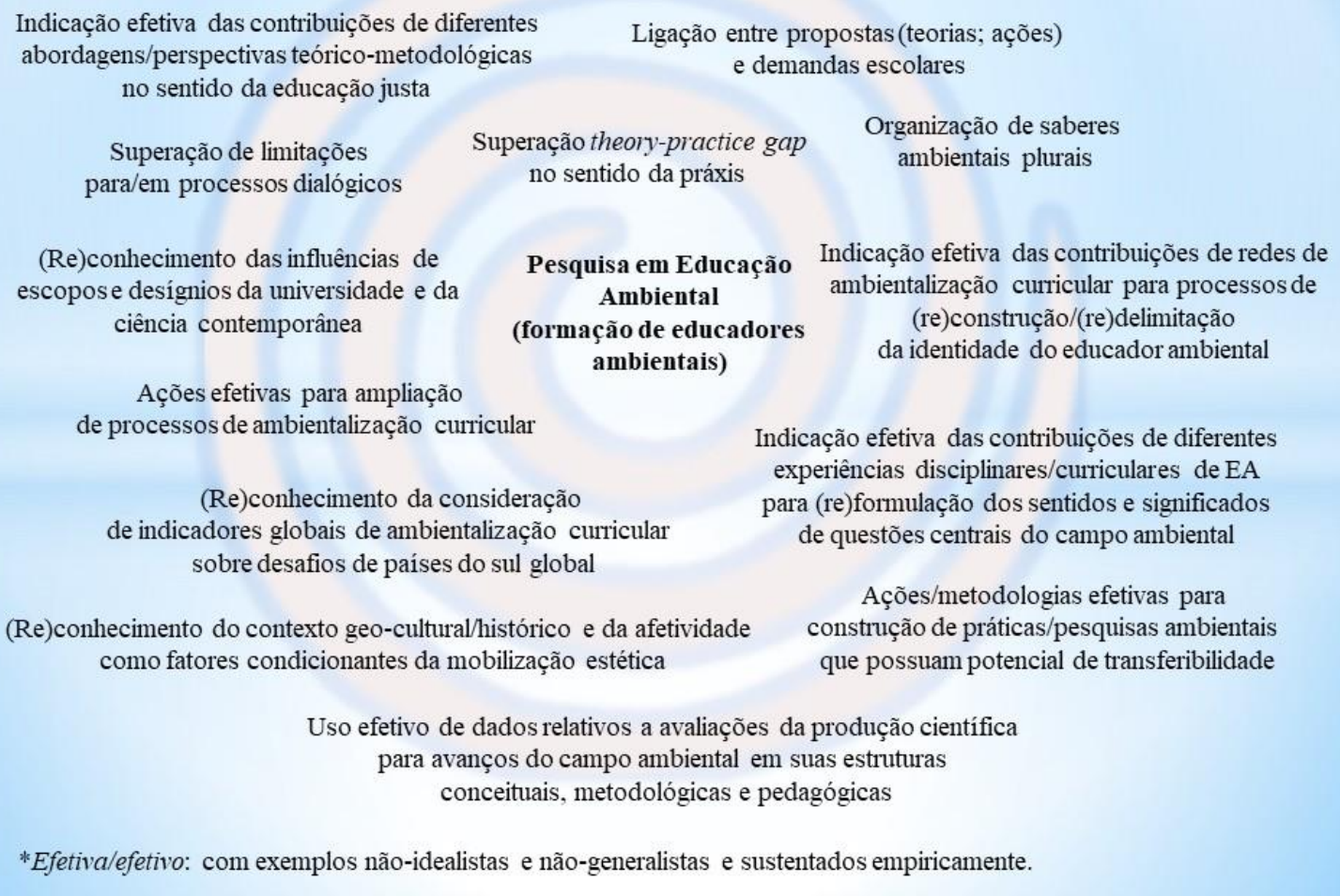

Figura 3: Mapa mental - PEA com ênfase na formação de educadores ambientais. Fonte: Autores (inspirado em Rodrigues et al., 2020).

O mapa mental é apresentado em forma de espiral (inspirado em Rodrigues et al., 2020), indicando a ausência de centralidade ou hierarquização das questões apresentadas. Como um rizoma, as questões devem ser compreendidas em sua relação complexa e relacional - cada questão pode ramificar em outros questionamentos; e o desenvolvimento de uma questão reverbera sobre as outras. Como conjunto integrado de questionamentos relevantes à 
elaboração, revisão e avaliação de pesquisas com foco na formação de educadores ambientais, o mapa mental (complementado pelas questões generativas apresentadas na seção anterior) é concebido como agenda de pesquisa e framework metodológico (parcial ou integral) no âmbito das PEA. Abaixo, apresentaremos algumas discussões relevantes considerando os pontos sensíveis indicados no mapa mental ${ }^{5}$.

\section{Transferência...possibilidades e limitações para o diálogo generativo}

Nessa última seção do artigo apresentaremos alguns contextos gerais do campo da PEA contemporâneo que consideramos relevantes para a "efetiva" ação sobre possibilidades e limitações de transferência (não generalização) da agenda de pesquisa/framework metodológico proposto (questões generativas e mapa mental - Figura 3) para a elaboração, revisão ou avaliação de pesquisas/ações com ênfase na formação de educadores ambientais, com especial consideração pela práxis. Essa contextualização é indicativa da importância em sempre se considerar as histórias (PAYNE, 2020) e particularidades geo-epistemológicas (CANAPARO, 2009) do campo na proposição ou utilização de recursos pedagógicos e metodológicos. Os contextos apresentados têm como base nossa experiência própria como professores e pesquisadores ativamente engajados no campo de produção da PEA e focam os "pontos sensíveis" indicados no mapa mental (Figura 3).

Apesar do contexto sociopolítico nacional estar constantemente tensionado por acordos globais e políticas locais que produzem "novas" dinâmicas e orientações no sentido da práxis sustentável ou ecológica ${ }^{6}$, a carência/ausência da práxis na (P)EA ainda é uma notável limitação histórica e recorrente no âmbito conceitual, metodológico e pedagógico (RODRIGUES, 2020a). A perspectiva de práxis discutida nesse texto sustenta-se na conceituação freiriana (FREIRE, 1981) de contexto de existência que ecoa da perspectiva relacional de subjetividadeobjetividade e ação-reflexão. Assim, uma pedagogia práxica vincula humanos e educação na condição de existência, sendo cruciais as noções de inacabamento (humanos como seres imperfeitos, incompletos e inconclusos, buscando ser mais), curiosidade epistemológica e conectividade com o mundo. Em perspectiva similar, e abordando especificamente o problema (talvez condição?) do theory-practice gap, o realismo crítico traz a perspectiva que não só o empirismo é explicativo da realidade, nem só o idealismo, mas um processo que surge do encontro relacional entre o empírico e o teórico (BHASKAR, 2008).

Se estamos entendendo que a práxis é um caminho, inclusive, para a elaboração teórica (teorizar a partir da e com a práxis, ou practice theory - ver SUND; PASHBY, 2020; PAYNE, 2018; PAYNE, 2020), a reflexão sobre quais práticas de EA estamos teorizando, e o que de fato estamos teorizando (corpus desta pesquisa), permite (re)conhecer lacunas na PEA. Complementarmente, a caracterização da ausência de relatos de pesquisa com metodologias e teorias dimensionadas historicamente sugere uma (re)orientação específica no modus operandi da PEA (PAYNE, 2020).

Exemplos observados na análise do corpus desta pesquisa são a fundamentação de trabalhos a partir dos Parâmetros Curriculares Nacionais e descrições históricas da constituição do campo da EA limitadas ao final do século XX e, de modo geral, descontextualizadas da prática investigada. A superação do gap entre teoria e prática (ver PAYNE, 2020) abre novas possibilidades para a práxis, processo crucial para a formação de educadores ambientais (ver

\footnotetext{
5 Para uma discussão aprofundada sobre o uso do mapa mental como recurso pedagógico/científico para elaboração, revisão e avaliação de pesquisas/práticas (em EA), ver Rodrigues et al., 2020.

${ }^{6}$ Não é objetivo desse trabalho discutir as distinções conceituais do campo ambiental; para esclarecimento, distinguimos os termos sustentável e ecológico pela compreensão das significativas particularidades geoepistemológicas (CANAPARO, 2009) desses dois conceitos.
} 
FREIRE, 1981, sobre a superação da separação entre teoria e prática tendo a realidade - social, cultural, histórica e política - como alicerce para a investigação).

Orientado pela realidade, o caminho da pesquisa é a construção dialógica a partir de diferentes perspectivas teórico-metodológicas que reconheçam e valorizem os lugares ocupados em múltiplos contextos contemporâneos da geopolítica mundial. Nesse contexto, a perspectiva de lugares ocupados parte da compreensão do território como espaço (co)habitado no qual as inter(-)ações estão sempre sujeitas às relações de poder (SANTOS, 1998). Contudo, entendemos que o diálogo entre teoria e prática, aliado às perspectivas locais e globais sobre a PEA não é trivial, ainda mais em se tratando da produção de conhecimentos (da ciência como empreendimento, ou "corpo coletivo de força generativa" (RODRIGUES, 2020b, 180p.) que, via de regra, ainda é muito ocidental e eurocentrada (ver RODRIGUES, 2020a). Auler e Delizoicov (2015), ao defenderem o pensamento Ciência-Tecnologia-Sociedade latinoamericano, argumentam que a pesquisa deve dar voz aos atores envolvidos em problemas historicamente esquecidos. Nesse sentido, dados empíricos demandariam perspectivas teóricometodológicas alicerçadas no compromisso com a transformação no sentido de processos educativos justos (decoloniais; descentralizados; históricos; práxicos - Rodrigues, 2020b) e com potencial generativo para a ação.

A defesa do novo, em termos da prática científica e (geopolítica) da produção de conhecimento, vem acompanhada da reflexão sobre o que é realmente novo como teoria, prática e práxis, compreendendo que a apropriação de novas teorias (especialmente as provenientes do Norte global) para a PEA de maneira acrítica e a-histórica reforça e reproduz dinâmicas de colonialismo acadêmico, fragilizando velhas perspectivas ecológicas e epistemologias do Sul (RODRIGUES, 2020a). Para Sousa Santos (2006) a realidade não deve ser reduzida ao que existe, pois deve incluir realidades ausentes devido ao silenciamento, repressão e marginalização; realidades que são ativamente produzidas como inexistentes.

Para Sousa Santos (2006), a prática científica deve ser reorientada da sociologia das ausências para a sociologia das emergências, resgatando a ecologia de saberes, de temporalidades, de produtividades, uma visão trans-escala e de reconhecimento do outro. Nos trabalhos analisados nesta pesquisa, essa questão se faz presente nos debates sobre os tempos escolares e os tempos da pesquisa, sobre as agências (atuação) dos comitês de ética em pesquisa que, embora cumprindo um papel de valorização da dimensão ética da pesquisa, muitas vezes, têm temporalidades que inviabilizam processos a longo prazo. Em alguns casos, passa também por entender a pesquisa como, de fato, colaborativa a partir de questões que podem vir do professor/educador ambiental e não somente definidas e pautadas pelos interesses do pesquisador, (re)posicionando as relações sujeito-sujeito na PEA.

A sociologia da produtividade é debatida e questionada a partir de suas tendências e consequências da produção rápida de ciência, das dinâmicas das plataformas avaliativas, das novas tecnologias de divulgação que contribuem para disjunção da nossa noção de tempo e espaço e sensação de aceleração. Uma (re)orientação da PEA, por meio do reconhecimento das realidades produzidas como inexistentes, pode fazer emergir o debate olvidado.

Por exemplo, a formação mediada pelas tecnologias digitais da informação e comunicação, nos processos que ocorrem na modalidade de Educação a Distância (EAD) nas licenciaturas do ensino superior, tem sido uma ausência na PEA. A modalidade EAD tem crescido no país (INEP, 2019), mas os significados para a formação do professor/educador ambiental têm sido pouco debatidos. No mapa mental, a superação para essas questões passa pelo (re)conhecimento do papel da universidade e da ciência contemporânea; pela organização dos saberes plurais, e é lograda quando buscamos a valorização dos contextos geopolíticos culturais e históricos na PEA, inclusive como fatores condicionantes da forma como aspectos estéticos são mobilizados em uma experiência (na natureza) (RODRIGUES, 2018, 2019). 
Ainda na caracterização das novas abordagens no campo da PEA, entendemos estar, em grande parte, relacionada com os diálogos pós (coloniais; humanos; estruturais etc.), na perspectiva de novas teorias como (novas) alternativas. Uma problemática linguísticasimbólica da caracterização do pós é o inevitável dualismo criado entre um velho já antiquado é um novo que emerge como superação daquilo que havia antes, vestindo o pós com características positivas (bom, melhor, avançado) na mesma medida em que veste teorias e práticas velhas com características negativas (ultrapassado, menos desenvolvido) (CARVALHO; STEIL; GONZAGA, 2020). Tal condição é agravada em caracterizações ahistóricas do pós (que são comuns, segundo RODRIGUES, 2020a), (re)criando uma dinâmica teleológica modernista de colonialismo que reproduz globalmente as novas teorias do Norte, reprimindo, por consequência, velhas teorias (ecológicas), inclusive cosmovisões indígenas (CARVALHO; STEIL; GONZAGA, 2020).

Para autores do Sul, há uma aposta no plural em termos de alternativas. Para Walsh (2013) as práticas insurgentes incitam, desafiam, transgredem e subvertem o pensamento colonial hegemônico e sua lógica civilizadora. São ditas insurgentes porque se constituem a partir de conhecimentos, práticas e sistemas civilizatórios e de vida que são diferentes, não hegemônicos da racionalidade ocidental. No que concerne a essa questão, observamos, em nossa análise empírica, que a PEA sobre a formação de professores e de educadores ambientais ainda é pouco permeável a esses temas. Isso pode ser decorrente dos processos formativos apresentados no GDP estarem centrados nos âmbitos formais de ensino, e pelo fato de ainda estarem muito regulados por estruturas que controlam e regulam as agências dos sujeitos a partir de indicadores globais de ambientalização curricular, que não necessariamente consideram os desafios particulares dos países do Sul global.

Aliás, a ausência das epistemologias (ecológicas) do Sul nas estruturas curriculares do Brasil é uma condição bastante particular, considerando a condição mais geral de um não lugar dos processos de ambientalização curricular no Brasil (ver exemplos em RODRIGUES 2015; RODRIGUES; PAYNE, 2017) e dos desafios da ambientalização curricular em âmbito global (ver PAYNE; RODRIGUES, 2012). Apesar da boa representatividade de pesquisas sobre ambientalização curricular (GUERRA; FIGUEIREDO, 2014) e no âmbito das produções sobre formação de educadores ambientais (RINK; MEGID NETO, 2013; TEIXEIRA; TORALES, 2014), a superação do idealismo teórico das propostas transversais de ambientalização curricular se apresenta como proeminente desafio epistemológico, metodológico e pedagógico da (P)EA. Nos trabalhos analisados, foi possível observar que a ambientalização curricular vai além dos cursos das áreas biológicas e ambientais, o que aponta para as diferentes possibilidades de prática da Política Nacional de EA, incluindo os processos formativos.

Ainda que busquemos um posicionamento a partir dos olhares e desafios latinoamericanos na discussão Norte-Sul, há um dinâmico panorama de acordos globais e de relações locais-globais que estão presentes no campo ambiental e precisam ser reconhecidos e discutidos na PEA. Como exemplo, podemos citar os atuais Objetivos de Desenvolvimento Sustentável e o Acordo de Paris. Como ação política, em 2015 o Brasil assinou o Acordo de Paris e assumiu o compromisso de implementar a Agenda 2030 para o Desenvolvimento Sustentável.

No Brasil, embora a PEA dirija um olhar crítico sobre essas políticas (ex. GADOTTI, 2008), como limite, temos observado que essa criticidade se traduz na valorização de um diálogo interno/nacional brasileiro (FIGUEIREDO; FREIRE, 2018) que faz com que as pesquisas não avancem na crítica aos discursos globais, desconsiderando/invisibilizando suas influências nas políticas locais. Apesar do discurso hegemônico oficial da Organização das Nações Unidas (ver NASCIMENTO, 2012, que considera ausentes as dimensões das culturas dos povos e a do poder nos discursos oficiais) estar pautado por um conservadorismo dinâmico (LIMA; LAYRARGUES, 2014), observamos que ausências e dificuldades de análise da 
conjuntura das políticas ambientais globais e seus desdobramentos nos processos educativos o reforçam, porque não estabelecem uma crítica, elaborando alternativas efetivas.

Concordando com Kothari, Demaria e Acosta (2014) ao afirmarem que, mais do que uma agenda de desenvolvimento pós 2015, precisamos de uma agenda de pós-desenvolvimento (ainda que nem todos tenham alcançado o bônus do desenvolvimento inerentemente à lógica do sistema, muitos países vivem as vulnerabilidades e o ônus do desenvolvimento enquanto países periféricos). Assim, discutir e desenvolver a PEA no plano da práxis contribui para ampliar a compreensão crítica dos fenômenos socioambientais, além de desenhar possibilidades de ação individuais e coletivas na vida. Também, possibilita o encontro com abordagens mais radicais de bem-estar (radical well-being approaches) (KOTHARI; DEMARIA; ACOSTA, 2014) que podem permear os processos educativos.

A partir das perguntas generativas e do mapa mental proposto, podemos destacar os saberes ambientais plurais e a efetiva cidadania como caminhos para essas abordagens mais radicais. De fato, o vínculo entre os processos educativos e a formação para a cidadania tem sido mais explorado na PEA do que a relação entre formação (muito situada nos processos formais) e os saberes plurais. Na PEA se discute que a formação para a cidadania pode gerar uma agência dos sujeitos com potencial transformador, questionando a ideia moderna de progresso e de desenvolvimento. No entanto, é necessário caracterizar como esses discursos de cidadania são valorizados na PEA, visto que o termo cidadania traz diferentes acepções (PINHÃO; MARTINS, 2016) e relações com a democracia (ARROYO, 2010).

A PEA pode contribuir com reflexões sobre os espaços de formação de profissionais e cidadãos, de práticas educativas e de produção de conhecimento que podem transformar valores, suscitar apropriações e ressignificações do ambiental e, também, transformar e criar novos modos de ver e agir no mundo. Isso inclui, especialmente nos contextos heterogêneos do Sul global (realidade cada vez mais presente também no Norte global), o diálogo com os saberes plurais em contraponto à racionalidade indolente (SOUSA SANTOS, 2006) que exclui outros modos de pensar.

Nesse sentido, os currículos de formação (com o foco na educação formal nos trabalhos analisados) precisariam transitar "entre os múltiplos saberes: científicos, populares e tradicionais, alargando a visão do ambiente e captando os múltiplos sentidos que os grupos sociais the atribuem" (CARVALHO, 2012, p.125). As abordagens mais radicais têm se apresentado como estratégias capazes de enfrentar o patriarcado, o produtivismo, o extrativismo e o antropocentrismo. Exemplos podem ser encontrados nas perspectivas do Swaraj na Índia (KOTHARI, 2018), do Buen vivir de origem andina (ACOSTA, 2012), do Ubuntu da África subsaariana (LE GRANGE, 2018), dentre outras. No entanto, o potencial de transferência dessas perspectivas para o campo da EA, nos âmbitos conceitual, metodológico e pedagógico, permanece sendo um desafio práxico da/para a PEA, considerando-se, especialmente, as histórias particulares (do campo ambiental e das perspectivas em análise) (PAYNE, 2020), as particularidades geoepistemológicas (CANAPARO, 2009) de contextos diversos e os limites da mudança (FAY, 1987).

\section{Considerações finais}

No presente trabalho utilizamos contextos da prática da PEA, por meio dos relatos de pesquisa dos trabalhos do GDP de formação do X EPEA para uma reflexão atualizada sobre os diálogos da PEA no Brasil, abrindo caminhos para formulações teóricas em uma perspectiva da práxis. Ao analisarmos os trabalhos do GDP, observamos uma tendência de pesquisa voltada para os âmbitos mais institucionais da formação dos professores/educadores - nas universidades. Também, observamos relatos de pesquisa comprometidos socialmente com problemas socioambientais e educativos. Por outro lado, identificamos a necessidade de 
explicitar questões filosóficas e epistemológicas que constituem essas pesquisas, que vem com a superação do gap entre teoria e prática e valorização dos diálogos Sul-Norte, inclusive de identificação das epistemologias do Sul. Ao encontrar o não lugar da questão ambiental na formação, apostamos que sua construção passa pela constituição de perspectivas alinhadas a propostas pós-desenvolvimentistas de sustentabilidade que inspiram novas práticas de formação e de pesquisa (ver RODRIGUES, 2020a). Assim, retomamos e aprofundamos o debate da PEA no Brasil, buscando oferecer um panorama do que tem sido investigado no GDP de formação do X EPEA.

Para além do presente texto, desenvolvemos questões generativas como potencial agenda de pesquisa, ou framework metodológico, que podem contribuir com a (des)(re)construção, ou (re)formulação de pesquisas e ações no âmbito da EA com foco na formação de educadores ambientais, com atenção especial à práxis. $\mathrm{O}$ debate apresentado no presente texto buscou contribuir para a consolidação de questões levantadas pela rede de pesquisadores que vem sendo formada ao longo dos EPEA, com vistas à inspiração para outras questões e caminhos para a PEA no Brasil.

Nesse sentido, a elaboração de questões generativas e do mapa mental se contextualiza como ação para o "esperançar", compreendendo que "enquanto necessidade ontológica, a esperança precisa da prática para tornar-se concretude histórica. É por isso que não há esperança na pura espera, nem tampouco se alcança o que se espera na espera pura, que vira, assim, espera vã" (FREIRE, 2005, p.11). Que o potencial generativo do que propomos se materialize em práxis...novos caminhos para uma velha esperança?

\section{Referências}

ACOSTA, A. Buen Vivir Sumak Kawsay. Una oportunidad para imaginar nuevos mundos. Quito: Abya Yala, 2012.

ARROYO, M. G. Educação e exclusão da cidadania. In: BUFFA, E.; ARROYO, M.; NOSELLA, P. (Orgs.). Educação e Cidadania: quem educa o cidadão? 14 ed. São Paulo: Cortez, 2010. p. 5-98. (Coleção questões para educar nossa época, Vol. 6).

AULER, D.; DELIZOICOV, D. Investigação de temas CTS no contexto do pensamento latinoamericano. Linhas Críticas, Brasília, v.21, n.45, p.275-296, 2015.

BHASKAR, R. A Realist Theory of Science. Oxon: Routledge, 2008.

CANAPARO, C. Geo-epistemology: Latin America and the location of knowledge. Oxford, UK: Peter Lang, 2009.

CARVALHO, L. M. Demandas e agendas da pesquisa em educação ambiental no Brasil: sentidos construídos a partir dos relatos dos Grupos de Discussão de Pesquisa em Educação Ambiental (GDPSEPEAS). Pesquisa em Educação Ambiental, Rio Claro, v.11, n.2. p.146-167, 2016.

CARVALHO, I. C. M. Educação ambiental e a formação do sujeito ecológico. 6 ed. São Paulo: Cortez, 2012.

CARVALHO, I. C. M.; STEIL, C. A.; GONZAGA, F. A. Learning from a more-than-human perspective: Plants as teachers. The Journal of Environmental Education, v. 51, n. 2, p.144-155, 2020.

FAY, B. Critical social science: liberation and its limits. New York: Cornell University Press, 1987. 
FIGUEIREDO J. B. A.; FREIRE L. M. Democracia, políticas públicas e práticas educativas representadas nas pesquisas de Educação Ambiental sobre formação de educadores/professores. Pesquisa em Educação Ambiental, Rio Claro, v.16, n.1, p.167-181, 2018.

FRACALANZA, H. As pesquisas sobre educação ambiental no Brasil e as escolas: alguns comentários preliminares. In: TAGLIEBER, J. E.; GUERRA, A. F. S. (Orgs.). Pesquisa em Educação Ambiental: pensamentos e reflexões de pesquisadores em Educação Ambiental. Pelotas: Editora Universitária/UFPel, 2004. p. 55-77.

FRACALANZA, H.; AMARAL, I. A.; MEGID-NETO, J.; EBERLIN, T. S. A educação ambiental no Brasil: panorama inicial da produção acadêmica. Ciências Em Foco, Campinas, v.1, n.1, 2013. Disponível em: <https://econtents.bc.unicamp.br/inpec/index.php/cef/article/view/9162>. Acesso em: 20 fev. 2020.

FREIRE; L. M.; FIGUEIREDO; J. B. A.; GUIMARÃES M. O papel dos professores/educadores ambientais e seus espaços de formação. Qual é a educação ambiental que nos emancipa? Pesquisa em Educação Ambiental, Rio Claro, v.11, n.2, p.120-128, 2016.

FREIRE, P. Pedagogia do oprimido. 10 ed. Rio de Janeiro: Editora Paz \& Terra, 1981.

FREIRE, P. Pedagogia da esperança: um reencontro com a Pedagogia do oprimido. 12 ed. São Paulo: Paz \& Terra, 2005.

GADOTTI, M. Educar para a sustentabilidade: uma contribuição à década da educação para o desenvolvimento sustentável. São Paulo: Instituto Paulo Freire, 2008.

GUERRA, A. F. S.; FIGUEIREDO, M. L. Ambientalização curricular na Educação Superior: desafios e perspectivas. Educ. rev., Curitiba, Edição Especial n.3, p.109-126, 2014.

Instituto Nacional de Estudos e Pesquisas Educacionais Anísio Teixeira - INEP. Resumo técnico do censo da educação superior 2017. [recurso eletrônico]. Brasília: Instituto Nacional de Estudos e Pesquisas Educacionais Anísio Teixeira, 2019. Disponível em: < http://portal.inep.gov.br/informacao-da-publicacao//asset_publisher/6JYIsGMAMkW1/document/id/6725796 $>$ Acesso em: $<1$ de fevereiro de 2020>

KOTHARI, A. Eco-Swaraj vs. Global Eco-Catastrophe. Asia Pacific Perspectives, São Francisco, v.15, n.2, p. 49-54, 2018.

KOTHARI, A.; DEMARIA, F.; ACOSTA, A. Buen Vivir, Degrowth and Ecological Swaraj: Alternatives to sustainable development and the Green Economy. Development, Roma, v. 57, n. 3-4, p.362-375, 2014.

LE GRANGE, L. The notion of Ubuntu and the (Post)Humanist condition. In: PETROVIC, J.; MITCHELL, R. (Ed.). Indigenous philosophies of education around the world. New York: Routledge, 2018. p. 40-60.

LIMA, G. F. C.; LAYRARGUES, P. P. Mudanças climáticas, educação e meio ambiente: para além do conservadorismo dinâmico. Educ. rev., Belo Horizonte, n. Especial 3, p. 73-88, 2014.

NASCIMENTO, E. P. Trajetória da sustentabilidade: do ambiental ao social, do social ao econômico. Estud. av., São Paulo, v.26, n.74, p. 51-64, 2012. 
PAYNE, P. "Amnesia of the moment" in environmental education. The Journal of Environmental Education, v. 51, n. 2, p. 113-143, 2020.

PAYNE, P. (Ed.) Special issue: Ecopedagogy as/in scapes. The Journal of Environmental Education, v. 49, n. 2, p.71-188, 2018.

PAYNE, P.; RODRIGUES, C. Environmentalizing the curriculum: a critical dialogue of south-north framings. Perspectiva, Erechim, v. 30, n. 2, p. 411-444, 2012. DOI: 10.5007/2175795x.2012v30n2p411.

PAYNE, P.; RODRIGUES, C.; CARVALHO, I. C. M.; SANTOS, L. M. F.; AGUAYO, C.; IARED, V. G. Affectivity in environmental education research. Pesquisa em Educação Ambiental, Rio Claro, Edição especial, v.13, p. 93-114, 2018.

PINHÃO, F.; MARTINS, I. Cidadania e Ensino de Ciências: questões para o debate. Revista Ensaio. Belo Horizonte, v.18, n. 3, p.9-29, Set./Dez. 2016. DOI 10.1590/1983-21172016180301.

RINK J.; MEGID NETO, J. Ambientalização curricular no ensino superior e formação de professores/educadores ambientais: um panorama das teses e dissertações brasileiras (1987-2009). In: - Encontro Pesquisa em Educação Ambiental, 7 EPEA, 2013, Rio Claro. Atas... Rio Claro: UNESP, 2013.p.1-12. Disponível em:< http://www.epea.tmp.br/epea2013_anais/pdfs/plenary/0155-1.pdf $>$ Acessado em: $<1$ de fevereiro de 2020>

RODRIGUES, C. O (não) lugar das sinergias motricidade-meio ambiente em contextos escolares. In: CORRÊA, D. A.; LEMOS, F. R. M.; RODRIGUES, C. (Orgs.). Motricidade Escolar. Curitiba: CRV, 2015. p. 147-172.

RODRIGUES, C. Limites da mudança e propostas vagabundas: perspectivas práxicas da educação ambiental. In: ARAÚJO, M. I. O.; NEPOMUCENO, A. L. O.; SANTANA, C. G. Educadores ambientais: caminhos para a práxis. Aracaju: Criação Editora, 2016.

RODRIGUES, C. Movement Scapes as ecomotricty in ecopedagogy. The Journal of Environmental Education, v. 49, n. 2, p.88-102, 2018. DOI: 10.1080/00958964.2017.1417222.

RODRIGUES, C. A ecomotricidade na apreensão da natureza: inter-ação como experiência lúdica e ecológica. Desenvolvimento e Meio Ambiente, Curitiba, Seção Especial: Técnica e Ambiente, v.51, p.8-23, 2019. DOI: 10.5380/dma.v51i0.63007.

RODRIGUES, C. (Ed.). Global politics of knowledge production in EER: 'New' theory and NorthSouth representations. The Journal of Environmental Education, v. 51, n. 2, p. 97-182, 2020a.

RODRIGUES, C. What's new? Projections, prospects, limits and silences in "new" theory and "post" North-South representations. The Journal of Environmental Education, v. 51, n. 2, p. 171-182, 2020b.

RODRIGUES, C.; PAYNE, P. Environmentalization of the physical education curriculum in Brazilian universities: Culturally comparative lessons from critical outdoor education in Australia. Journal of Adventure Education and Outdoor Learning, v. 17, n.1, p.18-37, 2017.

DOI:10.1080/14729679.2015.1035294.

RODRIGUES, C.; PAYNE, P. G.; LE GRANGE, L.; CARVALHO, I. C. M.; STEIL, C. A.; LOTZSISITKA, H.; LINDE-LOUBSER, H. Introduction: "New" theory, "post" North-South representations, praxis. The Journal of Environmental Education, v. 51, n. 2, p. 97-112, 2020.

SANTOS, M. O Espaço do Cidadão. 4 ed. São Paulo: Nobel, 1998. 
SOUSA SANTOS, B. Renovar la teoría crítica y reinventar la emancipación social (encuentros en Buenos Aires). Buenos Aires: CLACSO, 2006.

SOUZA, D. C.; SALVI, R. F. A pesquisa em educação ambiental: um panorama sobre sua construção. Ens. Pesqui. Educ. Ciênc., Belo Horizonte, v. 14, n. 3, p.111-129, 2012. DOI: 10.1590/198321172012140308.

SUND, L.; PASHBY, K. Delinking global issues in northern Europe classrooms. The Journal of Environmental Education, v. 51, n. 2, p. 156-170, 2020.

TEIXEIRA, C.; TORALES, M. A. A questão ambiental e a formação de professores para a educação básica: um olhar sobre as licenciaturas. Educ. rev., Curitiba, Edição Especial., n. 3, p.127-144, 2014 . DOI: $10.1590 / 0104-4060.38111$.

WALSH, C. Pedagogías decoloniales: prácticas insurgentes de resistir, (re)existir y (re)vivir. Tomo I. Quito, Ecuador: Ediciones Abya-Yala, 2013. 